\title{
Child Nutrition and Bone Health
}

\author{
Lucía Redondo-Cuevas $^{1}$ Jesús Sanchis-Chordà ${ }^{1}$ Pilar Codoñer-Franch ${ }^{1,2}$ \\ ${ }^{1}$ Department of Pediatrics, Obstetrics, and Gynecology, University of \\ Valencia, Valencia, Spain \\ 2 Department of Pediatrics, Dr. Peset University Hospital, \\ Valencia, Spain \\ Address for correspondence Lucía Redondo-Cuevas, BSc, MSc, \\ Department of Pediatrics, Obstetrics, and Gynecology, University of \\ Valencia, Avenida de Blasco Ibáñez 15, 46010 Valencia, Spain \\ (e-mail: lucia.redondo.cuevas@gmail.com).
}

J Child Sci 2018;8:e67-e74.

\begin{abstract}
Nutrition is one of the modifiable factors that contributes to bone accrual during childhood and adolescence, a critical period to prevent adult osteoporosis. Calcium and vitamin $D$ seem to be the most important nutrients for optimal bone growth. Requirements for calcium intake are different among countries and organizations, and exact recommendations are difficult to determine since other dietary factors directly affect calcium metabolism, such as salt intake and vitamin D levels. Some scientists have suggested that the actual calcium requirements are overestimated and that increased dairy intake does not necessarily translate to better bone health in adults. Moreover, calcium can be obtained from other natural foods, such as cruciferous vegetables (turnip greens, broccoli rabe, kale, broccoli, and cabbage), endive, sesame seeds, legumes, almonds, calcium-fortified vegetable beverages, and canned sardines. Vitamin D should be obtained from food combined with appropriate sun exposure, and if that is not enough, vitamin D supplements can be used. Diets

Keywords

- nutrition

- growth

- peak bone mass

- calcium absorption

- dairy comprised a complex combination of nutrients and foods, and dietary patterns in children and adolescents play a key role in bone formation. A dietary pattern that is high in vegetables and fruits and low in processed foods (containing large amounts of added sugar and salt) is necessary to achieve optimal bone formation. Finally, physical activity, particularly activities that apply large forces, is even more important than dietary factors to contribute to bone accrual.
\end{abstract}

\section{Introduction}

The fetal period, early life, childhood, and puberty are critical periods for the development and/or programming of metabolic systems, including the skeleton. Osteoporosis is described by the World Health Organization (WHO) as a "progressive systemic skeletal disease characterized by low bone mass and microarchitectural deterioration of bone tissue, with a consequent increase in bone fragility and susceptibility to fracture." Because of the morbidity of osteoporosis, the prevention of this disease and its associated fractures is considered essential to the maintenance of health, quality of life, and independence in the elderly population. ${ }^{1}$

received

June 29, 2018

accepted after revision

July 1,2018
Issue Theme Nutrition in Child Health Conditions; Guest Editor: Pilar Codoñer Franch, MD, PhD.
Peak bone mass attained during childhood and adolescence determines skeletal fragility in old age. ${ }^{2}$ Peak bone mass is the amount of bone acquired when accrual ceases or reaches a plateau at some point after the completion of growth and development. ${ }^{3}$ During growth and development, skeletal growth proceeds through the coordinated action of bone deposition and resorption to allow bones to expand and lengthen into their adult form. This process of bone modeling begins during the fetal growth period and continues until the end of the second decade of life. Bone modeling is sensitive to mechanical loading, emphasizing the importance of physical activity throughout growth., ${ }^{4,5}$

Copyright $\odot 2018$ Georg Thieme Verlag License terms KG Stuttgart · New York

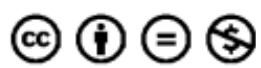


The most frequently used clinical indication of osteoporosis and fracture risk is bone mineral density (BMD). However, fracture resistance is determined by several factors that are difficult to measure: the strength of the bone, which in turn depends on its geometric properties (size, shape, and connectivity), the activities of the cells in the tissue, and the material properties of the tissue. The material properties of bone include the mineral content, mineral composition, mineral crystal size, and collagen matrix content and composition. ${ }^{6}$ In general, when osteoclast activity (the sole boneresorbing cell) is greater than osteoblast activity (responsible for bone formation), a higher bone fragility develops. ${ }^{7}$

The growth and maintenance of bone tissue are complex processes influenced by many factors ( $\mathbf{- F i g . 1} \mathbf{1}$ ):

Genetics, sex, and ethnicity: Heritable factors can explain 60 to $80 \%$ of the variability in bone mass and osteoporosis risk. ${ }^{4}$ Genome-wide association studies have identified more than 70 loci associated with adult bone density or fractures; however, only a few of these studies have been conducted in children. ${ }^{4,8}$ Males tend to have higher bone density and content, and they achieve it at a later age than females. ${ }^{9}$ Finally, racial differences in bone become apparent during childhood. In the United States, studies of areal BMD generally show the greatest values in African Americans followed by American white, Asian or Hispanic children. ${ }^{10}$

Intrauterine life: Maternal diet (particularly vitamin D deficiency), smoking, and physical activity modulate the bone mineral acquisition of the baby; moreover, both low birth size and poor childhood growth are directly linked to the risk of hip fracture later in life. ${ }^{11}$

Hormonal status: Several hormones affect bone mass. Estrogen plays an important part in maintaining BMD in women, and estrogen deficiency is associated with increased bone resorption and increased fracture risk. Androgens, growth hormones, and insulin-like growth factor-1 promote bone formation, whereas excess glucocorticoids both increase bone resorption and impair bone formation. ${ }^{12}$ Neighboring muscle and adipose tissue also exert significant control over bone remodeling. ${ }^{3}$

Physical activity: Bone growth and maintenance are critically stimulated by physical activity, and it is important at all ages. ${ }^{13}$ Regular physical activity is the key to optimizing peak bone mass, thus preventing osteoporosis later in life. ${ }^{14}$

Low-grade inflammatory state: It has been recognized that inflammatory cytokines of the immune system have a significant impact on the fine-tuned balance between bone resorption and bone formation. For example, cytokines, such as interleukin-6, interleukin- 1 and tumor necrosis factor- $\alpha$, suppress osteoblasts and stimulate osteoclast functions. Furthermore, oxidative stress and the generation of advanced glycation end products have emerged as links between inflammation and bone destruction. ${ }^{7}$

Gut microbiota: The microbiota interacts with the host to modulate bone density through different mechanisms ${ }^{15}$ :

1. Gut microbiota dysbiosis can lead to intestinal inflammation and bone inflammation.

2. Dietary or prebiotic fiber reaches the lower gut where the resident microbiota ferments the fiber to short-chain fatty acids, which can enhance calcium absorption and signal locally in the gut and in the bone.

3. The gut bacteria secrete factors and intestinal hormones, such as incretins and serotonin, that are known to regulate bone density.

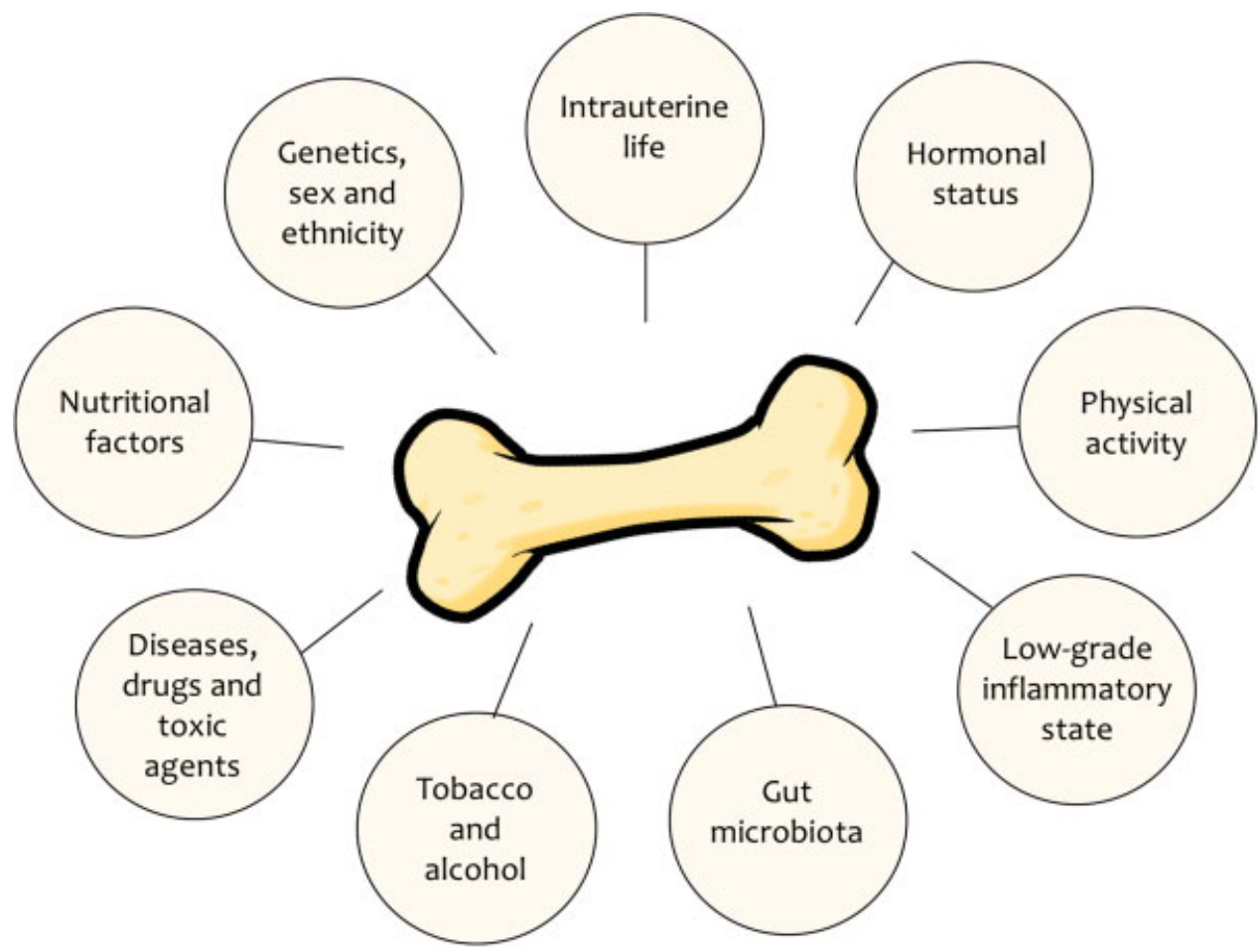

Fig. 1 Factors influencing bone formation during childhood and adolescence. 
Tobacco and alcohol use during childhood and adolescence have been associated with lower bone density levels. ${ }^{16}$

Many diseases, certain drugs, and toxic agents affecting children and adolescents can be associated with a reduction in bone accrual or a loss of bone mass and quality. For example, glucocorticoids result in significant reductions in bone formation because of the decreased differentiation of osteoblast precursors, impaired osteoblast function, and decreased osteoblast lifespan. ${ }^{3,17}$

Nutritional factors: The present review evaluates and summarizes current evidence of nutritional factors that promote maximal bone health from childhood through early to late adolescence.

\section{Nutritional Factors}

\section{Calcium}

Calcium is one of the main bone-forming minerals; over 99\% of total body calcium is found as calcium hydroxyapatite in bones and teeth, where it provides hard tissue with its strength.

\section{The Calcium Paradox}

Surprisingly, countries or populations with lower calcium intakes also have a lower prevalence of osteoporotic fractures, ${ }^{18,19}$ suggesting that environmental factors other than calcium intake play a key role in bone health. According to the Food and Agriculture Organization of the United Nations (FAO) ${ }_{1}^{18}$ most of the world's population consumes $500 \mathrm{mg}$ of calcium or less per day and few or no dairy products and yet experience low fracture rates. Currently, there is no satisfactory answer to the question behind the "calcium paradox." It is not surprising since it is known that bone is a complex tissue, and it is not impacted solely by calcium. ${ }^{20}$ However, an adequate intake of highly bioavailable calcium seems to be important to build bones in children.

\section{How Much Is Adequate Calcium?}

There is currently a considerable debate about the adequate recommended intake of calcium, and there is wide variation in the estimates of daily calcium requirements made by different expert authorities (-Table 1). Moreover, data on calcium intakes in children is too limited to draw conclusions about adequacy. ${ }^{21}$

Ludwig and Willett suggest that the recommended level of calcium intake in the United States is based predominately on balance studies of 3 weeks or less and likely overestimates actual requirements and greatly exceeds the recommended intake in the United Kingdom. ${ }^{28}$ According to the WHO, in countries with a high fracture incidence, only a minimum of 400 to $500 \mathrm{mg}$ of calcium intake is required to prevent osteoporosis in older people. ${ }^{29}$ It has been described that calcium homeostasis is maintained mainly by controlling gastrointestinal absorption and renal excretion of calcium. Children with low calcium intakes (227 or $359 \mathrm{mg} /$ day) demonstrated a mean fractional absorption of 61 or $63.1 \%$, respectively, approximately double that of children with calcium intakes close to the recommended dietary allowances. ${ }^{30}$ Moreover, children with low calcium intakes also reduce their renal excretion of calcium. ${ }^{30}$

Calcium requirements vary depending on dietary factors, such as the intake of vitamin $D,{ }^{31}$ sodium, ${ }^{4}$ and caffeine ${ }^{32}$ the presence of molecules modifying intestinal calcium absorption, such as lactose ${ }^{33}$ and other factors, such as physical activity. ${ }^{4,5}$ Calcium excretion increases with sodium intake because these minerals share some of the same transport systems in the proximal tubule. Lowering sodium intake by $2.3 \mathrm{~g}$ from 3.45 to $1.15 \mathrm{~g}$, for example, reduces the theoretical calcium requirement from 840 to $600 \mathrm{mg} .{ }^{34}$ This effect is more pronounced in Caucasians than in black adolescent girls. ${ }^{10}$ Determining an exact quantity of a nutrient while the rest of the diet and lifestyle changes results in a complex task.

Increasing calcium intake from dietary sources or by taking calcium supplements in adults produces small nonprogressive increases in $\mathrm{BMD},{ }^{35}$ and dairy consumption during adult life does not appear to be associated with reduced risk of fracture. ${ }^{36}$ During childhood and puberty, a small, biologically, and statistically significant positive effect of calcium intake on areal BMD and/or bone mineral content (BMC) accrual was observed, and this effect was largest in children who had the lowest intakes of calcium at baseline. ${ }^{4}$ However, calcium supplementation studies in pediatric

Table 1 Recommendation for calcium intake in several countries and organizations (mg/day)

\begin{tabular}{|l|l|l|l|l|l|l|l|}
\hline $\begin{array}{l}\text { Country/ } \\
\text { Organization }\end{array}$ & Toddlers & $\begin{array}{l}\text { Young } \\
\text { children }\end{array}$ & $\begin{array}{l}\text { Older } \\
\text { children }\end{array}$ & Adolescents & $\begin{array}{l}\text { Young } \\
\text { adult }\end{array}$ & $\begin{array}{l}\text { Middle-aged } \\
\text { adult }\end{array}$ & $\begin{array}{l}\text { Older } \\
\text { adult }\end{array}$ \\
\hline FAO/WHO, 2002 & 500 & 600 & 700 & 1,300 & 1,000 & 1,000 & 1,300 \\
\hline IOM, $2011^{23}$ & 700 & 1,000 & 1,300 & 1,300 & 1,000 & 1,000 & 1,200 \\
\hline EFSA, $2015^{24}$ & 450 & 800 & 800 & 1,150 & 1,000 & 950 & 950 \\
\hline Spain, $2010^{25}$ & 600 & 700 & 800 & $1,000-1,100$ & 900 & 900 & 1,000 \\
\hline UK, $1991^{26}$ & 350 & 450 & 550 & $800-1,000$ & 700 & 700 & 700 \\
\hline $\begin{array}{l}\text { Japan, } 2015^{27} \\
\text { Male } \\
\text { Female }\end{array}$ & 450 & 600 & 650 & $700-1,000$ & 800 & 650 & 700 \\
\hline
\end{tabular}

Abbreviations: EFSA, European Food Safety Authority; FAO/WHO, Food and Agriculture Organization of The United Nations/World Health Organization; IOM, Institute of Medicine; UK, United Kingdom. 
populations have shown that the relative gains in BMD were lost once supplementation was discontinued. ${ }^{30,37,38}$

\section{Effect of Dairy Intake on Bone Health during Childhood and Adolescence}

Some randomized controlled trials (RCTs) have been conducted on supplementation with dairy food and its effect on bone mass accrual during childhood and adolescence, but the results are still inconclusive. The National Osteoporosis Foundation conducted a systematic review of the predictors of peak bone mass ${ }^{4}$ in which they collected three 2-year RCTs showing increased gains in some bone sites with dairy food consumption. The first one was a school milk intervention in Chinese girls who consumed a low calcium quantity at baseline: 418 to $455 \mathrm{mg} \mathrm{Ca}$ /day. It was reported that increasing milk consumption (330 mL milk fortified with calcium) enhanced growth and bone mineral accretion. ${ }^{39}$ The second RCT was a trial performed with 195 girls (10-12 years old) in which no beneficial effects on bone were recorded after cheese supplementation after adjusting for differences in growth velocity among subjects. ${ }^{40}$ The third RCT showed the strongest evidence for a dairy food effect on bone mass accrual. Ninety-one healthy 15 to 18 years old girls in New Zealand were randomly allocated to either the control group or the dairy supplementation group. Calcium intake was similar at baseline, but at the end of study, it was significantly higher in the dairy-supplemented group (the number of servings of dairy food was not reported). After 2 years, there was a significantly greater increase in BMD at the trochanter, femoral neck, and lumbar spine in the high calcium group than in the control group. ${ }^{41}$

More recently, other RCTs have been published. In a population of 274 healthy girls aged 13 to 14 years with habitual dairy intakes of $\leq 1$ glass of milk/day and $\leq 600 \mathrm{mg} \mathrm{Ca} /$ day, a 1 -year intervention in which participants consumed recommended intakes of $\geq 1,200 \mathrm{mg} \mathrm{Ca} /$ day from low-fat milk or yogurt produced a small benefit compared with the effect seen in the control group in total-body minus head BMC. This difference was not statistically significant; however, the authors affirm that it has practical significance because it is estimated that increasing the bone mass of the elderly population by $5 \%$ would decrease hip fracture incidence by $50 \%{ }^{42}$ Vogel et al conducted an RCT with 181 girls aged 8 to 15.9 years who consumed $<800 \mathrm{mg} \mathrm{Ca} /$ day. ${ }^{43}$ They were randomly selected to receive an 18 -month dairy intervention ( 3 servings/day) or a control diet ( 2 servings/day). This study failed to support the recommended consumption of $>2$ servings dairy/day for adolescents based on BMD, BMC, and bone area for the total-body radius, lumbar spine, and total hip. Weber et al performed an RCT with 139 healthy children (7-10 years of age) implementing a family-centered behavioral modification and nutritional education program designed to increase dietary calcium intake. ${ }^{44}$ Although the program was successful in increasing calcium intake, it had no effect on bone accrual.

A prospective cohort study including over 22 years of follow-up concluded that greater milk consumption during the teenage years was not associated with a lower risk of hip fracture in older adults. ${ }^{45}$ Milk consumption in early life not only builds bone mass but also increases height, and height is a risk factor for hip fractures in later life. Further research is needed to clarify the role of early milk consumption and height in the prevention of hip fractures in older adults. ${ }^{45}$

\section{Food Sources of Calcium}

Milk allergies or lactose intolerance are situations that can lead to the elimination of dairy products as a calcium source. Vegan people do not allow dairy in their diets for various personal reasons. There are some suggested pathologies or situations in which the suitability of dairy consumption should be individually assessed, such as acne, ${ }^{46}$ mucus production, ${ }^{47}$ and gastrointestinal disorders, ${ }^{48}$ prostate cancer, ${ }^{49,50}$ and others. ${ }^{51,52}$ For these reasons, achieving a better understanding of both dairy and nondairy products as calcium sources is required.

Calcium sources should be evaluated based on both calcium content and bioavailability. Calcium absorption from milk is similar to that of other dairy products, even though the lactose content and the chemical form of calcium in cheese and yogurt are altered during processing. It is estimated that the calcium of both milk and yogurt and cheese have an absorption of $32.1 \%{ }^{57}$ Studies in humans have generally failed to demonstrate an enhancement of calcium absorption by lactose. ${ }^{53}$ Furthermore, the European Food Safety Authority (EFSA) Panel on Dietetic Products, Nutrition and Allergies, ${ }^{54}$ concludes that "a cause and effect relationship has not been established between the consumption of lactose and an increase in calcium absorption leading to an increase in calcium retention." Oxalates, phytates, and tannins are the main antinutritional components that negatively affect calcium absorption. However, culinary preparations in food grains, such as soaking, fermentation, and germination, reduce these antinutritional components, ${ }^{55}$ increasing calcium absorption. Roasting is another procedure to reduce phytic acid, as demonstrated in brown sesame seeds. ${ }^{56}$ Weaver et $\mathrm{al}^{57}$ described calcium absorption in humans from several food sources. Rhubarb and spinach are not good sources of calcium due to their apparently high levels of oxalates, the fractional absorption of calcium is $8.54 \%$ and $5.1 \%$, respectively. ${ }^{57}$ Additionally, low oxalate vegetables, such as those in the cruciferous group, have excellent calcium bioavailability, even better than dairy. For example, broccoli (61.3\%), bok choy (53.8\%), and kale (49.8\%) have a high calcium absorption. ${ }^{57}$ Pinto beans (26.7\%), red beans $(24.4 \%)$ or white beans $(21.8 \%)$ have a middle absorption rate for calcium. ${ }^{57}$ Fractional absorption of calcium from sesame seeds without hulls (20.8\%) and dry and roasted almonds (21.2\%) were assessed by Weaver and Plawecki in rat models. ${ }^{58}$ More studies are needed to contemplate other food sources of calcium and their bioavailability in humans.

Recommendations for dietary calcium in childhood and adolescence should be given based on both the content and absorption of calcium. In this context, - Table 2 highlights the food quantities that are calcium equivalents to 1 glass of milk.

\section{Vitamin D}

Taking calcium paired with vitamin D seems to be more beneficial for bone health than taking calcium alone. Vitamin D 
Table 2 Food calcium equivalents to 1 glass of milk (240 mL)

\begin{tabular}{|l|}
\hline $\begin{array}{l}2 \text { units of small yogurt ( } 125 \mathrm{~g} \text { each one) or } 1 \text { unit of } \\
\text { big yogurt ( } 200 \mathrm{~g})\end{array}$ \\
\hline $\begin{array}{l}1.5 \text { ounces of hard cheese (cheddar, mozzarella, } \\
\text { Swiss, Parmesan) or } 2 \text { cups of cottage cheese }\end{array}$ \\
\hline 1 unit of small yogurt from sheep milk ( $125 \mathrm{~g})^{\text {a }}$ \\
\hline $\begin{array}{l}0.5 \text { serving (approx. } 100 \mathrm{~g}) \text { of turnip greens, broccoli } \\
\text { rabe, kale, broccoli, cabbage, or endive }\end{array}$ \\
\hline $\begin{array}{l}1-2 \text { tablespoons of unhulled roasted and triturate sesame } \\
\text { seeds }\end{array}$ \\
\hline $\begin{array}{l}1-2 \text { tablespoons of tahini from toasted and unhulled } \\
\text { sesame seed }\end{array}$ \\
\hline $\begin{array}{l}1 \text { serving ( } 200 \mathrm{~g}) \text { of legumes soaked prior cooking }+2 \\
\text { handful of roasted almonds }\end{array}$ \\
\hline $\begin{array}{l}\text { 2-3 canned sardines, or the equivalent in other fish } \\
\text { with soft bones ( } 45 \mathrm{~g})\end{array}$ \\
\hline 1 glass ( $140 \mathrm{~mL}$ ) of vegetable beverage calcium fortified \\
\hline $130 \mathrm{~g}$ of calcium-set tofu (made with a calcium salt) \\
\hline 10 dried figs \\
\hline
\end{tabular}

Data of food composition were obtained from US Department of Agriculture. $^{59}$

${ }^{\mathrm{a}}$ Data were obtained from the product label (Cantero del Letur). ${ }^{59}$

${ }^{b}$ Quantity based in calcium content and absorption percentage.

'Data were provided by the food manufacturer (Lima, distributed in Spain by Biocop). ${ }^{59}$

and its metabolites are a crucial part of the endocrine system that controls calcium homeostasis in the whole body. The primary role of vitamin D during growth is to increase intestinal calcium absorption so that sufficient calcium is available for bone mineralization. ${ }^{31}$

Eight RCTs have been included in a review by Weaver et $\mathrm{al}^{4}$; half of these RCTs provided evidence for a beneficial effect of vitamin D supplementation on bone accrual, and the other half showed no effect of vitamin D supplementation on bone. The effect of vitamin $\mathrm{D}$ on bone accrual is more pronounced in those with a lower baseline 25-hydroxyvitamin D status. Furthermore, it has been suggested that there may be a "critical window" during which the skeleton is most receptive to the effects of vitamin $D$, since the vitamin $D$ effect is more pronounced in prepubertal or early pubertal girls than in postpubertal girls. ${ }^{3}$

Vitamin D can be acquired via food sources. Vitamin D is found naturally in fatty fish (e.g., mackerel, tuna, and sardines) and egg yolks. It is necessary to take into consideration how the hens are maintained and fed and whether the fish is caught in the sea or grown in special farms, but in general, the content of vitamin D in food is too low to satisfy vitamin D requirements. $^{60}$

An important way to get vitamin D is through sun exposure, since humans can synthetize it in the skin under the influence of ultraviolet (UV) radiation. An adequate daily dose of UV solar radiation is considered beneficial for health due to the synthesis of vitamin $D$ that occurs. The season and latitude influence the cutaneous synthesis of vitamin D. During the winter, when living above and below $\sim 33^{\circ}$ latitude, very little, if any, vitamin D can be produced in the skin from sun exposure. ${ }^{61}$ For example, in Valencia (Spain), at around noon in January, it takes more than 2 hours of solar exposure to obtain the recommended daily dose of vitamin $\mathrm{D}(1,000 \mathrm{IU})$, whereas it takes only 7 minutes in July, 11 minutes in April, and 31 minutes in October. In this study, a body exposure of $10 \%$ (face, neck, and hands) for winter (January), 25\% (neck, hands, and arms) for spring (April) and summer (July), and 15\% (face, neck, hands, and half arms) for autumn (October) was assumed. Exposure times to produce erythema were obtained to determine the skin cancer risk, and these were longer than the times required to obtain the recommended vitamin D daily dose. ${ }^{62}$ Moderate sun exposure is important enough to synthetize vitamin $\mathrm{D}$ but not too much to increase the skin cancer risk.

Finally, another source of vitamin D is dietary supplementation. The daily recommended dose for children and adolescents varies widely around the word, but all guidelines unanimously agree that serum levels of 25-hydroxyvitamin $\mathrm{D}$ of $<25 \mathrm{nmol} / \mathrm{L}\left(10 \mathrm{ng} / \mathrm{mL}\right.$ ) should be avoided at all ages. ${ }^{63}$

\section{Protein Intake}

Protein makes up 50\% of bone volume and approximately onethird of its mass; it provides the structural matrix of bone. Collagen and a variety of noncollagenous proteins form the organic matrix of bone. However, it has been described that dietary protein (particularly animal protein) increases calcium urinary excretion. ${ }^{34}$ It was proposed that increasing dietary protein that contains sulfur-containing amino acids results in a metabolic acid load that requires buffering from alkali stores in the bone, resulting in skeletal calcium loss. This theory has been refuted by a recent systematic review and meta-analysis that concluded that no adverse effects in bone health were observed due to higher protein intakes. ${ }^{64}$ It seems that the increased urinary calcium excretion is due to the positive effect of protein in intestinal calcium absorption. ${ }^{64}$

Much of what is known regarding dietary protein and bone health comes from adult studies; limited work in children and adolescents has been done. However, an adequate dietary protein intake seems important for optimal acquisition and maintenance of bone mass, ${ }^{64}$ as has been described in prospective studies. ${ }^{4}$

\section{Other Nutrients}

Bone formation is a complex biological process and involves many other nutrients. Magnesium, vitamin $\mathrm{K}$, vitamin $\mathrm{C}$, manganese, copper, zinc, and iron could have some positive effects on bone formation since they are cofactors in enzymes responsible for bone metabolism and collagen synthesis. ${ }^{4}$ However, there are limited studies to substantiate these potential effects. Zofkova et al reviewed the effect of trace elements on bone health. ${ }^{65}$ Zinc, copper, manganese, magnesium, iron, selenium, boron, and fluoride seem to be beneficial for bone health. However, cadmium, cobalt, and lead are toxic. Furthermore, excessive intake of certain beneficial elements (fluoride, iron, magnesium, and zinc) can also have toxic effects; for example, a high intake of fluoride damages bone integrity. 


\section{Dietary Patterns}

Human subjects eat a variety of different foods and beverages throughout the day, not single nutrients. For this reason, it is important take into consideration the dietary pattern rather than the individual nutrients. Movassagh and Vatanparast reviewed the impact of dietary patterns on bone health. ${ }^{66}$ Western dietary patterns, mainly characterized by high intakes of soft drinks, fried foods, meat, processed products, sweets, desserts, and refined grains, were inversely associated with BMD and directly associated with bone resorption and formation biomarkers and the risk of osteoporosis, compared with "healthier" dietary patterns emphasizing the intake of fruit, vegetables, whole grains, poultry, fish, nuts, legumes, and low-fat dairy products. ${ }^{66}$ Most of the studies had cross-sectional designs and were conducted in adults. Only one of the described clinical trials was conducted on adolescents. ${ }^{67}$ Twenty male adolescents ( $\sim 12.9$ years of age) were enrolled to follow a 28-day Mediterranean-type diet. Compared with the consumption of their habitual diets, adolescents significantly increased the absorption and retention of dietary calcium, and consequently, calcium utilization efficiency was significantly improved. The calcium intake during the Mediterranean diet was lower than in the habitual diets; in fact, the percentage of calcium provided by dairy products decreased. These results suggest that the Mediterranean diet leads to increased calcium bioavailability.

Regarding the detrimental effect of Western diets on bone health during growth, it is important to highlight the especially negative effect of soft drinks. ${ }^{4,68}$

\section{Physical Activity}

Physical activity in childhood, particularly activities that apply large forces, is one of the most powerful preventive strategies in the fight against osteoporosis. ${ }^{5}$ It has even been suggested that physical activity during the critical growing years can compensate for a low calcium intake. ${ }^{69}$

\section{Conclusions}

Bone health should be prioritized during childhood, adolescence, and even during the fetal stage of development. These stages are especially important for building bones and developing habits to prevent adult osteoporosis. Bone health is affected by multiple factors, of which nutrition is a modifiable one. Moreover, physical activity is even more important than dietary factors to contribute to bone accrual (-Fig. 2). As much as possible, outdoor physical activity should be promoted to allow for adequate sun exposure and vitamin $\mathrm{D}$ synthesis, another key factor to optimize bone health.

Currently, dietary patterns in children and adolescents are low in fruits and vegetables and high in processed foods with large amounts of added sugar and salt, which negatively affect bone health. At the same time, a dramatic increase in sedentary behavior in children is the current reality, and an alarming rate of alcohol intake and smoking among adolescents is described. ${ }^{70}$ For these reasons, urgent food and lifestyle policies addressing these topics are needed to effectively prevent chronic diseases, such as osteoporosis.

Calcium and vitamin D seem to be the most important nutrients for optimal bone growth. The exact calcium requirements are difficult to determine since other dietary factors directly affect calcium metabolism, such as salt intake and vitamin D levels. Some scientists suggest that the actual requirements of calcium are overestimated and that increased dairy intake does not necessarily translate to better bone health in adults. In any case, when dairy products are recommended, it is important to avoid sweetened dairy, since refined sugar adversely affects bone health. Finally, if dairy cannot be eaten or is avoided for personal motives, calcium can be obtained from

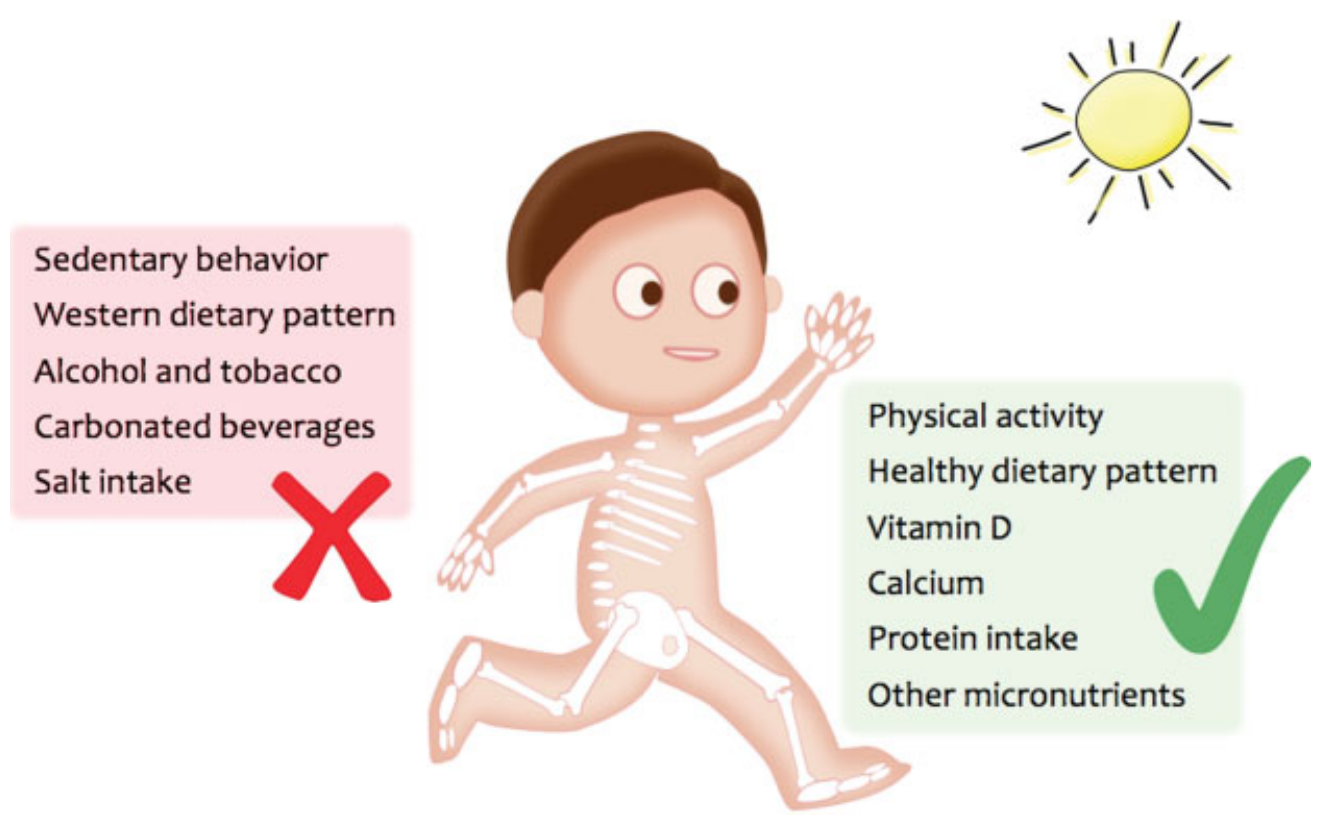

Fig. 2 Lifestyle habits to optimize bone health. 
other natural foods, such as cruciferous vegetables (turnip greens, broccoli rabe, kale, broccoli, and cabbage), endive, sesame seeds, legumes, almonds, or canned sardines.

\section{Conflict of Interest}

None.

\section{References}

1 Word Health Organization. WHO scientific group on the assessment of osteoporosis at primary health care level. Summary Meeting Report Brussels, Belgium, 2004. Available at: http:// www.who.int/chp/topics/Osteoporosis.pdf. Accessed April, 2018

2 Stagi S, Cavalli L, Iurato C, Seminara S, Brandi ML, de Martino M. Bone metabolism in children and adolescents: main characteristics of the determinants of peak bone mass. Clin Cases Miner Bone Metab 2013;10(03):172-179

3 Gordon CM, Zemel BS, Wren TA, et al. The determinants of peak bone mass. J Pediatr 2017;180:261-269

4 Weaver CM, Gordon CM, Janz KF, et al. The National Osteoporosis Foundation's position statement on peak bone mass development and lifestyle factors: a systematic review and implementation recommendations. Osteoporos Int 2016;27(04):1281-1386

5 Gunter KB, Almstedt HC, Janz KF. Physical activity in childhood may be the key to optimizing lifespan skeletal health. Exerc Sport Sci Rev 2012;40(01):13-21

6 Faibish D, Ott SM, Boskey AL. Mineral changes in osteoporosis: a review. Clin Orthop Relat Res 2006;443(443):28-38

7 Pietschmann P, Mechtcheriakova D, Meshcheryakova A, FögerSamwald U, Ellinger I. Immunology of osteoporosis: a minireview. Gerontology 2016;62(02):128-137

8 Rocha-Braz MG, Ferraz-de-Souza B. Genetics of osteoporosis: searching for candidate genes for bone fragility. Arch Endocrinol Metab 2016;60(04):391-401

9 Alswat KA. Gender disparities in osteoporosis. J Clin Med Res 2017;9(05):382-387

10 Walker MD, Novotny R, Bilezikian JP, Weaver CM. Race and diet interactions in the acquisition, maintenance, and loss of bone. J Nutr 2008;138(06):1256S-1260S

11 Cooper C, Westlake S, Harvey N, Javaid K, Dennison E, Hanson M. Review: developmental origins of osteoporotic fracture. Osteoporos Int 2006;17(03):337-347

12 Golden NH, Abrams SA. Committee on Nutrition. Optimizing bone health in children and adolescents. Pediatrics 2014;134(04): e1229-e1243

13 Going SB, Farr JN. Exercise and bone macro-architecture: is childhood a window of opportunity for osteoporosis prevention? Int J Body Compos Res 2010;8:1-9

14 Zulfarina MS, Sharkawi AM, Aqilah-S N ZS, Mokhtar SA, Nazrun SA, Naina-Mohamed I. Influence of adolescents' physical activity on bone mineral acquisition: a systematic review article. Iran J Public Health 2016;45(12):1545-1557

15 McCabe L, Britton RA, Parameswaran N. Prebiotic and probiotic regulation of bone health: role of the intestine and its microbiome. Curr Osteoporos Rep 2015;13(06):363-371

16 Heaney RP, Abrams S, Dawson-Hughes B, et al. Peak bone mass. Osteoporos Int 2000;11(12):985-1009

17 Maggioli C, Stagi S. Bone modeling, remodeling, and skeletal health in children and adolescents: mineral accrual, assessment and treatment. Ann Pediatr Endocrinol Metab 2017;22(01):1-5

18 Food and Agriculture Organization of the United Nations. Milk and dairy products in human nutrition. Rome (Italy), 2013. Available at: http://www.fao.org/docrep/018/i3396e/i3396e.pdf. Accessed April, 2018

19 Hegsted DM. Fractures, calcium, and the modern diet. Am J Clin Nutr 2001;74(05):571-573
20 Nieves JW, Lindsay R. Calcium and fracture risk. Am J Clin Nutr 2007;86(06):1579-1580

21 Looker AC. Dietary calcium: recommendation and intakes around the world. In: Weaver CM, Heaney RP, eds. Calcium in the Human Health, 1st ed. Totowa, NJ: Humana Press; 2006: $105-127$

22 Food and Agriculture Organization. Human vitamin and mineral requirements. Report of a joint FAO/WHO expert consultation, Bangkok, Thailand. World Health Organization, Rome, 2002. Available at: http://www.fao.org/docrep/004/y2809e/y2809e00. htm. Accessed April, 2018

23 Ross AC, Manson JE, Abrams SA, et al. The 2011 report on dietary reference intakes for calcium and vitamin $D$ from the Institute of Medicine: what clinicians need to know. J Clin Endocrinol Metab 2011;96(01):53-58

24 European Food Safety Authority. EFSA Panel on Dietetic Products, Nutrition and Allergies (NDA); Scientific Opinion on Dietary Reference Values for calcium. EFSA J 2015;13:4101 Available at www.efsa.europa.eu/efsajournal. Accessed April, 2018

25 Federación Española de Sociedades de Nutrición. Alimentación y Dietética. Ingestas Dietéticas de Referencia (IDR) para la Población Española. Act Diet 2010;14:196-197

26 Dietary reference values for food energy and nutrients for the United Kingdom. Report of the Panel on Dietary Reference Values of the Committee on Medical Aspects of Food Policy. Rep Health Soc Subj (Lond) 1991;41:1-210

27 The Japan Dietetic Association. Dietary Reference Intakes for Japanese, 2015. Available at: http://www.mhlw.go.jp/file/06-Seisakujouhou-10900000-Kenkoukyoku/Overview.pdf. Accessed April, 2018

28 Ludwig DS, Willett WC. Three daily servings of reduced-fat milk: an evidence-based recommendation? JAMA Pediatr 2013;167 (09):788-789

29 Word Health Organization. Diet, nutrition, and the prevention of chronic diseases: report of a joint WHO/FAO expert consultation. WHO Technical Report Series, No. 916 (TRS 916), Geneva, 2003. Available at: http://apps.who.int/iris/bitstream/handle/10665/426 65/WHO_TRS_916.pdf;jsessionid=CA68047B8489AC043623D73CC7E6882C? sequence $=1$. Accessed April, 2018

30 Pettifor JM. Calcium and vitamin D metabolism in children in developing countries. Ann Nutr Metab 2014;64(Suppl 2): $15-22$

31 Fleet JC. The role of vitamin D in the endocrinology controlling calcium homeostasis. Mol Cell Endocrinol 2017;453:36-45

32 Wikoff D, Welsh BT, Henderson R, et al. Systematic review of the potential adverse effects of caffeine consumption in healthy adults, pregnant women, adolescents, and children. Food Chem Toxicol 2017;109(Pt 1):585-648

33 Areco V, Rivoira MA, Rodriguez V, Marchionatti AM, Carpentieri A, Tolosa de Talamoni N. Dietary and pharmacological compounds altering intestinal calcium absorption in humans and animals. Nutr Res Rev 2015;28(02):83-99

34 Food and Agriculture Organization of the United Nations. Human vitamin and mineral requirements. Report of a joint FAO/WHO expert consultation Bangkok, Thailand, 2001. Available at: http:// www.fao.org/3/a-y2809e.pdf. Accessed April, 2018

35 Tai V, Leung W, Grey A, Reid IR, Bolland MJ. Calcium intake and bone mineral density: systematic review and meta-analysis. BMJ 2015;351:h4183

36 Bolland MJ, Leung W, Tai V, et al. Calcium intake and risk of fracture: systematic review. BMJ 2015;351:h4580

37 Ward KA, Cole TJ, Laskey MA, et al. The effect of prepubertal calcium carbonate supplementation on skeletal development in Gambian boys-a 12-year follow-up study. J Clin Endocrinol Metab 2014;99(09):3169-3176

38 Lambert HL, Eastell R, Karnik K, Russell JM, Barker ME. Calcium supplementation and bone mineral accretion in adolescent girls: an 18-mo randomized controlled trial with 2-y follow-up. Am J Clin Nutr 2008;87(02):455-462 
39 Du X, Zhu K, Trube A, et al. School-milk intervention trial enhances growth and bone mineral accretion in Chinese girls aged 10-12 years in Beijing. Br J Nutr 2004;92(01):159-168

40 Cheng S, Lyytikäinen A, Kröger H, et al. Effects of calcium, dairy product, and vitamin $\mathrm{D}$ supplementation on bone mass accrual and body composition in 10-12-y-old girls: a 2-y randomized trial. Am J Clin Nutr 2005;82(05):1115-1126, quiz 1147-1148

41 Merrilees MJ, Smart EJ, Gilchrist NL, et al. Effects of diary food supplements on bone mineral density in teenage girls. Eur J Nutr 2000;39(06):256-262

42 Lappe JM, Begley MA, Des Mangles JC, Laughlin A, McMahon DJ, Schawartz MC.. Clinical trial of dairy in adolescent girls: effect on bone accrual. In: Weaver CM, Daly R, Bischoff-Ferrari $\mathrm{H}$, eds. Nutritional Influences of Bone Health. Montreal, Canada: Springer;2016:261-267

43 Vogel KA, Martin BR, McCabe LD, et al. The effect of dairy intake on bone mass and body composition in early pubertal girls and boys: a randomized controlled trial. Am JClin Nutr 2017;105(05):1214-1229

44 Weber DR, Stark LJ, Ittenbach RF, Stallings VA, Zemel BS. Building better bones in childhood: a randomized controlled study to test the efficacy of a dietary intervention program to increase calcium intake. Eur J Clin Nutr 2017;71(06):788-794

45 Feskanich D, Bischoff-Ferrari HA, Frazier AL, Willett WC. Milk consumption during teenage years and risk of hip fractures in older adults. JAMA Pediatr 2014;168(01):54-60

46 Melnik BC. Evidence for acne-promoting effects of milk and other insulinotropic dairy products. Nestle Nutr Workshop Ser Pediatr Program 2011;67:131-145

47 Bartley J, McGlashan SR. Does milk increase mucus production? Med Hypotheses 2010;74(04):732-734

48 Deth R, Clarke A, Ni J, Trivedi M. Clinical evaluation of glutathione concentrations after consumption of milk containing different subtypes of $\beta$-casein: results from a randomized, cross-over clinical trial. Nutr J 2016;15(01):82

$49 \mathrm{Lu} \mathrm{W}$, Chen H, Niu Y, Wu H, Xia D, Wu Y. Dairy products intake and cancer mortality risk: a meta-analysis of 11 population-based cohort studies. Nutr J 2016;15(01):91

50 Aune D, Navarro Rosenblatt DA, Chan DS, et al. Dairy products, calcium, and prostate cancer risk: a systematic review and metaanalysis of cohort studies. Am J Clin Nutr 2015;101(01):87-117

51 Turner KM, Keogh JB, Clifton PM. Red meat, dairy, and insulin sensitivity: a randomized crossover intervention study. Am J Clin Nutr 2015;101(06):1173-1179

52 Melnik BC. Milk-the promoter of chronic Western diseases. Med Hypotheses 2009;72(06):631-639

53 Cashman KD. Calcium intake, calcium bioavailability and bone health. Br J Nutr 2002;87(Suppl 2):S169-S177

54 European Food Safety Authority. EFSA Panel on Dietetic Products, Nutrition and Allergies (NDA); Scientific Opinion on the substantiation of health claims related to lactose and increase in calcium absorption leading to an increase in calcium retention (ID 668) pursuant to Article 13(1) of Regulation (EC) No 1924/2006. EFSA J 2011;9:2234 Available at https://efsa.onlinelibrary.wiley.com/ doi/epdf/10.2903/j.efsa.2011.2234. Accessed April, 2018

55 Gupta RK, Gangoliya SS, Singh NK. Reduction of phytic acid and enhancement of bioavailable micronutrients in food grains. J Food Sci Technol 2015;52(02):676-684

56 Embaby $\mathrm{H}$. Effect of heat treatments on certain antinutrients and in vitro protein digestibility of peanut and sesame seeds. Food Sci Technol Res 2011;17:31-38

57 Weaver CM, Proulx WR, Heaney R. Choices for achieving adequate dietary calcium with a vegetarian diet. Am J Clin Nutr 1999;70(3, Suppl):543S-548S

58 Weaver CM, Plawecki KL. Dietary calcium: adequacy of a vegetarian diet. Am J Clin Nutr 1994;59(5, Suppl):1238S-1241S

59 US Department of Agriculture, Agricultural Research Service, Nutrient Data Laboratory. USDA National Nutrient Database for Standard Reference, Release 28. Version Current: September 2015, slightly revised May 2016. Available at: https://ndb.nal.usda.gov/ ndb/. Accessed April, 2018

60 Göring H, Koshuchowa S. Vitamin D - the sun hormone. Life in environmental mismatch. Biochemistry (Mosc) 2015;80(01):8-20

61 Wacker M, Holick MF. Sunlight and vitamin D: a global perspective for health. Dermatoendocrinol 2013;5(01):51-108

62 Serrano MA, Cañada J, Moreno JC, Gurrea G. Solar ultraviolet doses and vitamin D in a northern mid-latitude. Sci Total Environ 2017; 574:744-750

63 Bouillon R. Comparative analysis of nutritional guidelines for vitamin D. Nat Rev Endocrinol 2017;13(08):466-479

64 Shams-White MM, Chung M, Du M, et al. Dietary protein and bone health: a systematic review and meta-analysis from the National Osteoporosis Foundation. Am J Clin Nutr 2017;105(06): 1528-1543

65 Zofkova I, Davis M, Blahos J. Trace elements have beneficial, as well as detrimental effects on bone homeostasis. Physiol Res 2017;66 (03):391-402

66 Movassagh EZ, Vatanparast H. Current evidence on the association of dietary patterns and bone health: a scoping review. Adv Nutr 2017;8(01):1-16

67 Seiquer I, Mesías M, Hoyos AM, Galdó G, Navarro MP. A Mediterranean dietary style improves calcium utilization in healthy male adolescents. J Am Coll Nutr 2008;27(04):454-462

68 Høstmark AT, Søgaard AJ, Alvær K, Meyer HE. The Oslo Health Study: A dietary index estimating frequent intake of soft drinks and rare intake of fruit and vegetables is negatively associated with bone mineral density. J Osteoporos 2011. doi:http://dx.doi. org/10.4061/2011/102686

69 Anderson JJ. Calcium requirements during adolescence to maximize bone health. J Am Coll Nutr 2001;20(2, Suppl):186S-191S

70 Word Health Organization. Adolescents: health risks and solutions, 2018. Available at: http://www.who.int/mediacentre/factsheets/fs345/en/. Accessed April, 2018 